\title{
IOT Based Weather Reporting System
}

\author{
Devesh Kumar Srivastava, Pawan Kumar Giri, Govind Yadav, Manish Kumar, Jay Singh
}

\begin{abstract}
The IOT based Climate Detailing Framework is proposed to get Live announcing of climate conditions on farming utilized regions. It needs to screen temperature, stickiness, twist, light and downpour level on enormous ground fields. The Web of Things (IoT) innovation behind the framework is expected to offer a financially effective answer for screen climate conditions. The framework is observing the natural conditions and sends the data to the cloud and information is demonstrated like graphical measurements on a site page, and are anticipated the destructive climate conditions like tempest, dryness.
\end{abstract}

Keywords: Climate, Temperature, Stickiness, Twist, Downpour, Tempest, Dryness.

\section{INTRODUCTION}

Current innovation developments are for the most part planned for checking different sorts of exercises. They progressively seem to address human issues. The greater part of this innovation is centered around the powerful observing of different exercises. A compelling ecological checking framework is basic for observing and assessing conditions if the endorsed degree of boundaries is surpassed (e.g., temperature, light and dampness) [1]. The paper presents a climate framework that is useful for horticulture. This climate framework depends on Web of Things (IOT). It is furnished with ecological sensors utilized for estimations at a specific spot and report them continuously on cloud. To achieve this, it is utilized Arduino Uno and distinctive natural sensors like DS18B20. Climate framework will contain different climate stations that will gather information and send live information in the cloud through Wi-Fi association. From the estimations will be determined isobars, isotherms for land guide and this will help for climate forecast.

Revised Manuscript Received on June 28, 2020.

* Correspondence Author

Devesh Kumar Srivastava*, Researcher, Dept. of EEE, GL Bajaj Institute of Technology and Management, Gr. Noida, U.P., India. E-mail: devsrivastav15@gmail.com1

Pawan Kumar Giri, Associate Professor, Dept. of EEE, GL Bajaj Institute of Technology and Management, Gr. Noida, U.P., India

Govind Yadav, Associate Professor, Dept. of EEE, GL Bajaj Institute of Technology and Management, Gr. Noida, U.P., India

Manish Kumar, Associate Professor, Dept. of EEE, GL Bajaj Institute of Technology and Management, Gr. Noida, U.P., India

Jay Singh, Associate Professor, Dept. of EEE, GL Bajaj Institute of Technology and Management, Gr. Noida, U.P., India

(c) The Authors. Published by Blue Eyes Intelligence Engineering and Sciences Publication (BEIESP). This is an open access article under the CC BY-NC-ND license (http://creativecommons.org/licenses/by-nc-nd/4.0/)

\section{SYSTEM DESIGN}

Framework engineering is the theoretical model that characterizes the structure, conduct, and more perspectives on a framework. The motivation behind the framework is to gather ecological information from climate stations situated at various land facilitates. The framework proposed is a

propelled answer for climate observing that utilizes IoT to make its constant information effectively open over a wide range. The framework manages checking climate and atmosphere changes and forestalls/conjecture farming dangers. The information will be put away on a server devoted to the framework, with the likelihood to get to the information through the Web from a site page, facilitated by the committed server. The framework level design is appeared in Figure 1.

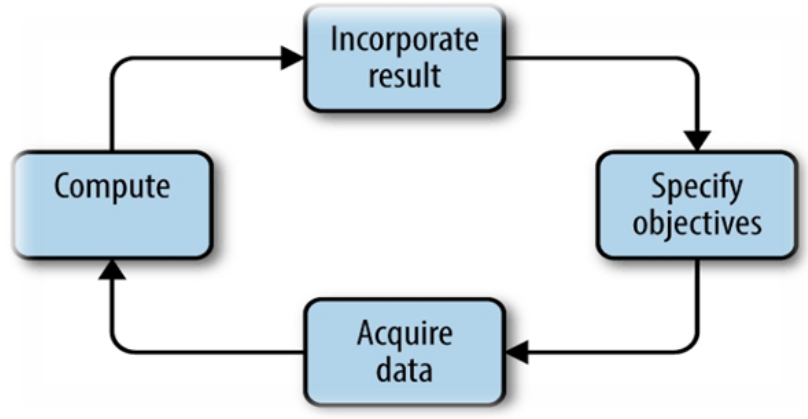

Figure 1. General Design of the System.

\section{A. ACQUISITION DEVICES}

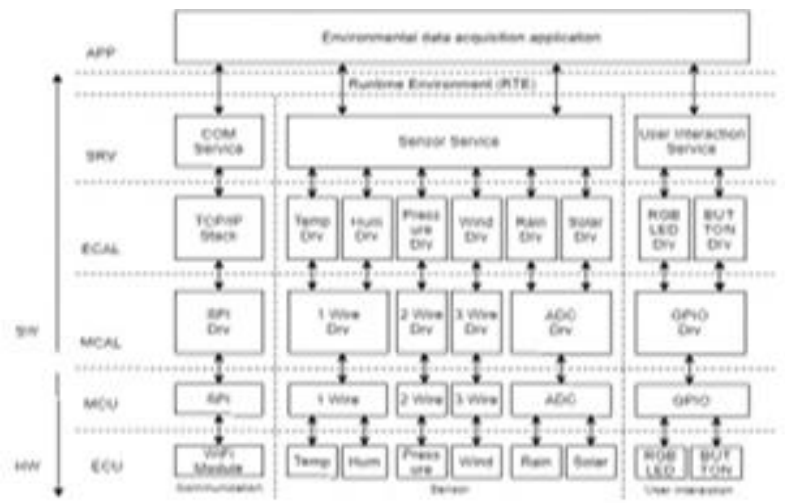

Figure 2. General Architecture of IOT

Every segment of either sensor or correspondence will be acknowledged as following the idea of the nonexclusive segment. Each segment has a stack partitioned by layers, which furnishes the application with numerous administrations through the RTE interface [2].

Published By:

Blue Eyes Intelligence Engineering

\& Sciences Publication

(C) Convriaht: All riahts reserved. 


\section{IOT Based Weather Reporting System}

All in all, the gadget will have the accompanying structure appeared in Figure 2. Practically, gadgets gather information about nature and transmit it to the IoT organize. Rundown of sensors that will be utilized in the framework are: temperature, stickiness, pneumatic force, wind speed and course (Anemometer), raindrop and light sensors. The information stream and the control signals are introduced in the useful graph of Figure 3.

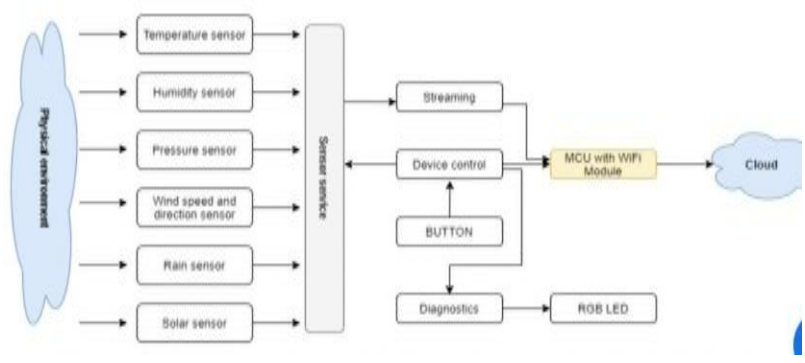

Figure 3. Functional and Dataflow Program For The IOT Devices

\section{B. ACQUISITION SERVER}

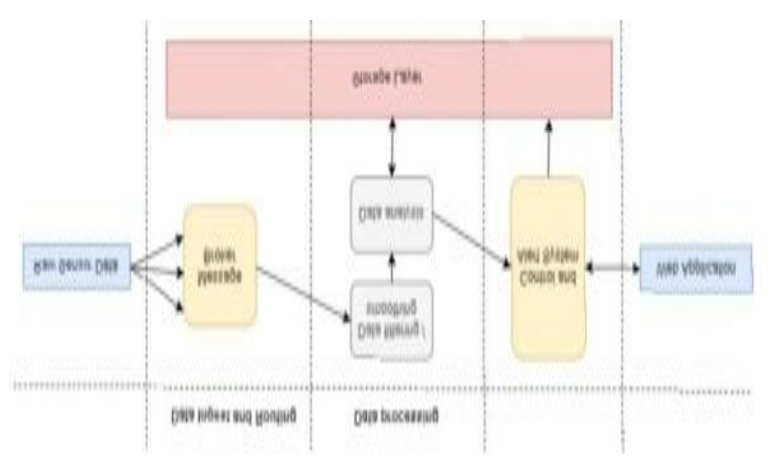

Figure 4. IOT Server

The usage of the obtaining server speaks to a total individual framework, particularly with respect to sensors availability because of the design idea. On account of the securing server, the information stream from the sensors is coordinated through the correspondence module, and separately the information demands from the sensors are supplanted with solicitations to the system. Procurement server can likewise speak with the standard Web arrange through the Wi-Fi organize. Because of the sensor reflection in the sensor administration layer, the application utilizes the information from sensors as though it would be straightforwardly associated with the gear on which it runs. The information is being aggregated in the Message Agent which at that point passes the information to its endorsers, which on account of our framework is the Information Preparing layer, where all the information sifting, smoothing and investigation is finished. The point by point dataflow graph of the IOT server is introduced in the Figure 4.

\section{ARDUINO UNO}

Arduino is an open source instrument for appearing well and good and control a greater amount of the physical world than your work station. It's an open-source physical figuring stage dependent on a basic miniaturized scale controller board, and an improvement situation for composing programming for the board. In this framework Arduino Uno is utilized like an advancement board, so as to get information from sensor and sent through Wi-Fi Module to the cloud.

\section{WI-FI MODULE}

The ESP8266 NodeMCU is a minimal effort Wi-Fi microchip with a full TCP/IP stack and microcontroller ability. This little module permits microcontrollers to associate with a Wi-Fi system and make basic TCP/IP associations utilizing Hayes-style orders. In this framework Wi-Fi module is utilized to send information to the cloud so as to process information and yield in a UI.

\section{E. TEMPERATURE SENSOR}

This framework is utilized as DHT-11 waterproof sensor as shown in Figure 5. It is valuable when you have to quantify something far away, or in wet conditions. Since they are advanced, you don't get any sign corruption significantly over significant distances.

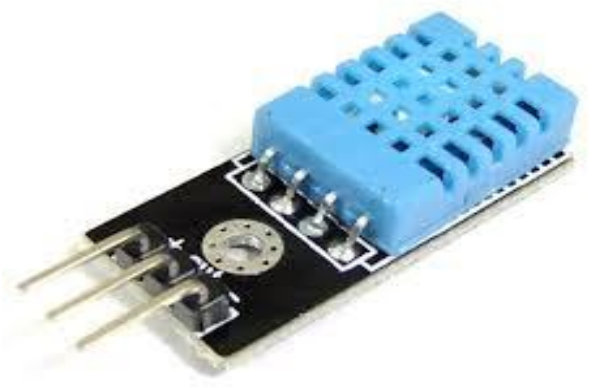

Figure 5. Temperature Sensor

These 1-wire computerized temperature sensors are genuinely exact $\left( \pm 0.5^{\circ} \mathrm{C}\right.$ over a significant part of the range) and can offer up to 12 bits of exactness from the installed digitalto-simple converter.

They work extraordinary with any microcontroller utilizing a solitary computerized pin.

\section{F. Soil Moisture Sensor}

The soil moisture sensor is one sort of sensor used to measure the volumetric substance of water inside the dirt shown in figure 6 . As the straight gravimetric element of soil dampness needs taking out, drying, just as test weighting. These sensors measure the volumetric water content not legitimately with the assistance of some different guidelines of soil like dielectric steady, electrical opposition, in any case cooperation with neutrons, and substitution of the dampness content.The connection among the determined property just as dampness of soil ought to be balanced and may change dependent on environmental variables like temperature, sort of soil, in any case electric conductivity. The microwave emanation which is reflected can be affected by the dampness of soil just as basically utilized in horticulture and remote detecting inside hydrology.

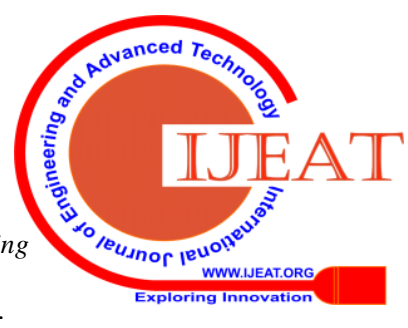




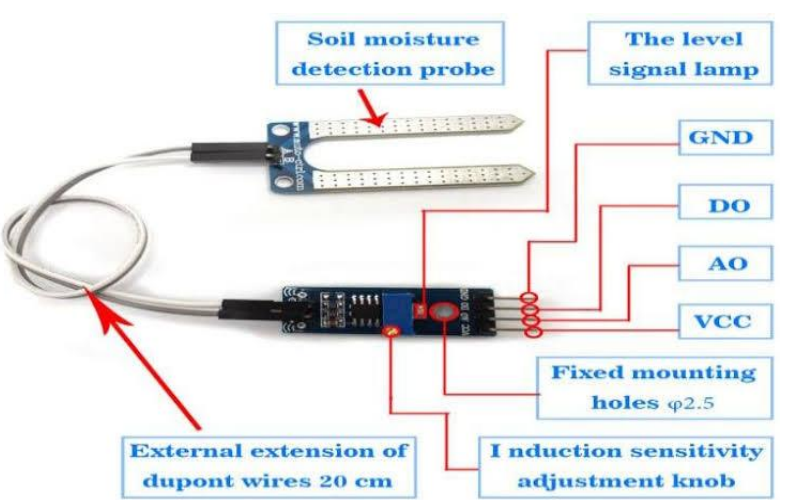

Figure 6. Soil Moisture Sensor

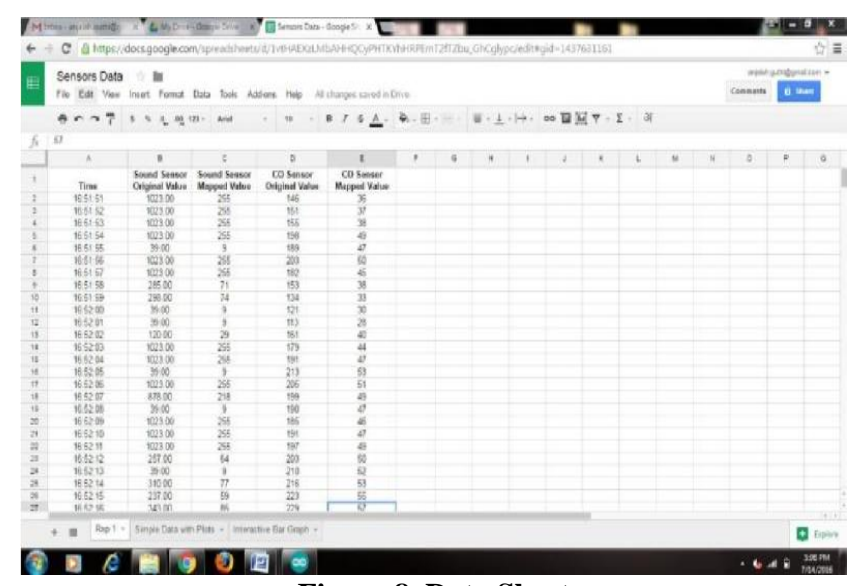

Figure 8. Data Sheet

\section{CONCLUSION}

The motivation behind the framework is to gather natural information from gadgets situated at various land facilitates. The framework proposed is a propelled answer for climate observing that utilizes IoT to make its continuous information effectively open over an exceptionally wide range. In this paper authors have indicated a well design of the framework, and a portion of the segments of the framework.

\section{REFERENCES}

1. Nashwa El-Bendary, Mohamed Mostafa M. Fouad, Rabie A Ramadan, Soumya Banerjee and Aboul Ella Hassanien, "Smart Environmental Monitoring Using Wireless Sensor Networks", K15146_C025.indd, 2013.

2. Andrei bragarenco galina marusic, "internet of things system for environmentalmapacquisition",2019https://jes.utm.md/wpconte nt/upload/sites/20/2020/01/jes-2019-4 88-102.pdf.

3. SoilmoistureSensorhttps://www.elprocus.com/soil-moisture-sensorworking and-applications/

4. Decagon Devices Read the "List of peer-reviewed publications using Decagon soil moisture sensors". Retrieved: 20 July 2015.

5. Nashwa El-Bendary, Mohamed Mostafa M. Fouad, Rabie A. Ramadan, Soumya Banerjee and Aboul Ella Hassanien, "Smart Environmental Monitoring Using Wireless Sensor Networks",K15146_C025.indd, 2013

6. Grzegorz Lehmann, Andreas Rieger, Marco Blumendorf, SahinAlbayrakDAI, "A 3-Layer Architecture for Smart Environment Models"/A model-based approach/Labor Technische University Berlin, Germany 978-1-4244-5328-3/10 (C) IEEE,2010.

7. https://www.researchgate.net/publication/320188557_wireless_sensor_ networks_based-internet_of_thing_for_agro-climatic_parameters

\section{AUTHORS PROFILE}

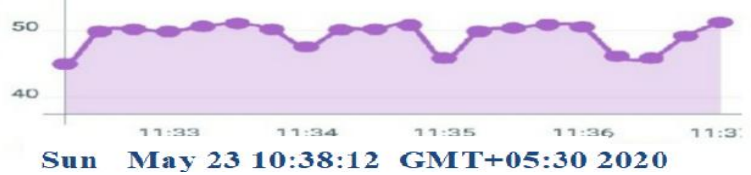

Figure 7. Data monitoring

The figure $7 \& 8$ shows the web server page and data sheet respectively which permits us to screen and control the framework. By entering IP address of server which is set for observing we will get the relating page. The site page gives the data about the force of sound and the CO level varieties in that specific district, where the inserted observing framework is set.

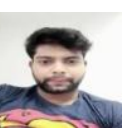

Er. Devesh Kumar Srivastava is Pursuing B.Tech, in "Electrical and Electronics Engineering" from "G.L. Bajaj Institute of Technology And Management" Gautam Buddh Nagar. His Final Project is "IOT Based Weather Report

System".

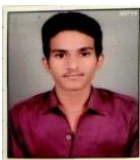

Er. Pawan Kumar Giri is Pursuing B.Tech, in "Electrical and Electronics Engineering" from "G.L. Bajaj Institute of Technology And Management" Gautam Buddh Nagar. His Final Project Is "IOT Based Weather Reporting System".

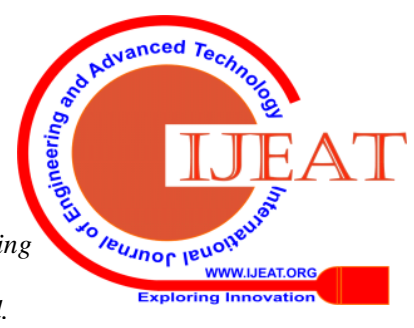




\section{IOT Based Weather Reporting System}

Govind yadav is a B.tech final year student of "GL Bajaj Institute of Technology and Management" , Greater Noida. He is pursuing his degree in "Electrical and Electrical Engineering". His Final Project Is "IOT Based Weather Reporting System".

Manish kumar is a B.tech final year student of "GL Bajaj Institute of Technology and Management", Greater Noida. He is pursuing his degree in "Electrical and Electrical Engineering". His Final Project Is "IOT Based Weather Reporting System".

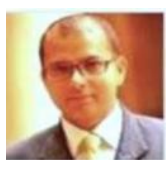

Jay Singh received his Ph.D., M.Tech and B.Tech degrees, all in Electrical Engineering, where he received his Ph.D. degree (in year 2015) from Indian Institute of Technology (ISM) Dhanbad M. Tech. (in year 2010) from Maharshi Dayanand University Rohtak, India and B.Tech (in year 2005) degree from Madan Mohan Malviya Engineering College Gorakhpur (Currently known as Madan Mohan Malviya University of Technology) India. Dr. Singh has been awarded as best faculty from several institutions. Also he has received the best paper award st from 1 IEEE Uttar Pradesh Conference in year 2015. He has published 46 research papers in reputed international journals / conferences.

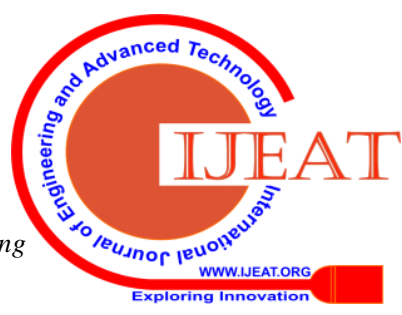

